Pteridines

Vol. 2, 1990, pp. $47-49$

Short Communication

\title{
Post Mortem Neopterin Concentrations in Sudden Infant Death Syndrome (SIDS)
}

\author{
Edda Ambach, Wolfgang Tributsch \\ Institut für Gerichtliche Medizin der Universität Innsbruck, Müllerstraße 44, A-6020 Innsbruck, Austria \\ Dietmar Fuchs, Arno Hausen. Gilbert Reibnegger and Helmut Wachter ${ }^{1)}$ \\ Institut für Medizinische Chemie und Biochemie, Universität Innsbruck, Fritz-Pregl-Straße 3, \\ A-6020 Innsbruck, Austria
}

(Received March 1990)

\section{Introduction}

The sudden infant death syndrome (SIDS) is the main cause of mortality in the first year of life in developed countries: $3-4$ out of 1000 newborns die from SIDS $(1,2)$. The term SIDS is accepted worldwide since 1969. SIDS cases die suddenly and unexpected in connection with negative anamnesis. Necropsy gives no adequate indication for any cause of death. The principal characteristic of SIDS is that the death occurs while asleep. In general the babies are totally perspired.

Most of SIDS cases occur within the first year of life: $50 \%$ of SIDS-cases occur before the 4 th months and $85 \%$ till the 6 th month of life. In this period many vaccinations are carried out, therefore a relationship between vaccination and SIDS was discussed. In addition, there is a maximum of SIDS-cases during winter months, which is correlated to cold weather fronts. Some $40-75 \%$ of SIDS victims have evidence of respiratory tract infection (3).

On the other hand immaturity of certain cerebral regions such as formatio reticularis, as the center of respiratory regulation, inay be a cofactor in the etiology of SIDS (4). However, the pathogenesis of SIDS is still unknown, inspite of interdisciplinary programs.

In this study we evaluated neopterin concentrations in SIDS cases, which were obtained during necropsy.

\footnotetext{
1) To whom correspondence should be addressed.
}

\section{Material and Methods}

At necropsy we obtained urine and serum of 19 SIDS cases, all less than 8 months of age. In addition, we examined 59 serum and 35 urine specimens of 37 adults, who died for various causes (mainly cardiac death), and who did not show any signs of inflammatory disorders at necropsy. Twenty-eight serum and 14 urine specimens stem from 17 cases, who had obvious signs of inflammatory disorders at necropsy (10 infections, 5 carcinoma. 2 intensive care unit patients). We examined neopterin and creatinine concentrations in serum and urine using HPLC (5). Statistical comparison of groups was done by Wilcoxon rank test.

\section{Results}

In Table 1 serum concentrations of neopterin, creatinine, neopterin per creatinine. and urine neopterin per creatinine are summarized. High frequencies of increased neopterin and creatinine concentrations as well as ratio in urine and serum were observed in the entire group of cases: whereas serum neopterin and creatinine concentrations were increased in most cases compared with the upper normal limits, only approximately $50^{\circ}$ of all cases had increased urine neopterin

When comparing the samples according to the necropsy findings. serum neopterin was higher in cases with inflammatory disorders $(z=2.62, p<0.01)$ and with SIDS $z=4.29$. $p<0.01$ ) compared to those 
Table 1. Post mortem neopterin and creatinine concentrations in cases with and without signs of inflammatory disorders ( $\mathrm{n}$; median; 25 th -75 th percentile)

\begin{tabular}{llllc}
\hline & \multicolumn{2}{l}{$\begin{array}{l}\text { First } \\
\text { examinations only }\end{array}$} & $\begin{array}{l}\text { Upper } \\
\text { normal } \\
\text { limits }\end{array}$ \\
\cline { 2 - 4 } & 73 & 46 & $1-69$ & \\
\hline Age $(\mathrm{yr})$ & 73 & 77 & $28-185$ & 8.7 \\
$\begin{array}{l}\text { Serum neopterin } \\
(\mathrm{nmol} / \mathrm{L})\end{array}$ & 68 & 312 & $201-631$ & 100 \\
$\begin{array}{l}\text { Serum creatinine } \\
(\mu \mathrm{mol} / \mathrm{L})\end{array}$ & 68 & 172 & $101-487$ & 90 \\
$\begin{array}{l}\text { Serum neopterin per } \\
\text { creatinine }(\mu \mathrm{mol} / \mathrm{mol})\end{array}$ & 49 & 256 & $197-863$ & 251 \\
$\begin{array}{l}\text { Urine neopterin per } \\
\text { creatinine }(\mu \mathrm{mol} / \mathrm{mol})\end{array}$ & & & & \\
\hline
\end{tabular}

without signs of inflammatory disorders. Serum creatinine did not differ between the groups. Also urine neopterin levels were higher in cases with inflammatory disorders $(z=4.07, p<0.01)$ and with SIDS $(\mathrm{z}=4.02, \mathrm{p}<0.01)$ compared to those without inflammatory disorders.

Statistical analyses showed that the time interval between death and sample collection influenced neopterin and creatinine concentration in serum but not in urine (Table 2). When separating samples in two groups, group I comprising cases obtained less than 10 hours after death and group II with samples obtained later, significantly higher serum neopterin and creatinine concentrations were seen in group II. In Table 2 the dependence from time of sample collection is shown for the cases without inflammatory disorders. Serum neopterin $(z=2.52, p=0.01)$ and serum creatinine $(z=2.73, p<0.01)$ were significantly higher in the samples obtained later. The ratio between serum neopterin and creatinine concentrations did not differ between the groups $(z=0.13, n$. s. $)$. No difference was seen comparing urine neopterin levels.
These observations were confirmed in sequentially collected necropsy samples of one case who died after gunshot: Urine neopterin/creatinine did not differ between 5 samples collected 4-19 hours after death, but an immediate increase of serum neopterin and creatinine was observed $8-10$ hours after death.

\section{Discussion}

Our data show that neopterin evaluation can serve as a useful tool to aid diagnosis of inflammatory disorders in post mortem examinations. Cases with inflammatory disorders had higher serum and urine neopterin levels than those without signs of inflammation. Similar results were obtained when SIDS cases are compared to cases without inflammation.

By in vivo and in vitro studies it was demonstrated that increased neopterin concentrations reflect cellmediated immune activation. Large amounts of neopterin are released from macrophages on stimulation with interferon-gamma $(5,6)$. Therefore, increased neopterin concentrations in SIDS-babies support the hypothesis, that infectious complications are involved in the pathogenesis of SIDS.

Further, our data show that serum neopterin and creatinine concentrations after death increase with time. Absolute serum concentrations are only representative for the in vivo concentrations within the first 8 hours after death. In contrast, urine neopterin per creatinine levels are stable for at least 24 hours.

The reason for the increase of neopterin after death is not clear. It appears reasonable that immunologic activation of e. g. macrophages after death is involved. However, also serum creatinine levels increase. Thus, influx of small molecules from extracellular space into the vessels could be involved. However, further studies are needed to clarify this point.

Table 2. Post mortem neopterin and creatinine concentrations in cases without signs of inflammatory disorders divided into two groups by the time of examination (n; median; 25 th -75 th percentile)

\begin{tabular}{|c|c|c|c|c|c|c|}
\hline \multirow[b]{3}{*}{ Age (yr) } & \multicolumn{6}{|c|}{ Time of examination from death } \\
\hline & \multicolumn{3}{|c|}{$<10$ hours } & \multicolumn{3}{|c|}{$>10$ hours } \\
\hline & 10 & 54 & $37-71$ & 26 & 63 & $55-74$ \\
\hline $\begin{array}{l}\text { Serum neopterin } \\
(\mathrm{nmol} / \mathrm{L})\end{array}$ & 10 & 15 & $10-28$ & 26 & 50 & $22-102$ \\
\hline $\begin{array}{l}\text { Serum creatinine } \\
(\mu \mathrm{mol} / \mathrm{L})\end{array}$ & 9 & 151 & $123-174$ & 24 & 358 & $276-742$ \\
\hline $\begin{array}{l}\text { Serum neopterin per creatinine } \\
(\mu \mathrm{mol} / \mathrm{mol})\end{array}$ & 9 & 118 & $83-161$ & 24 & 152 & $54-226$ \\
\hline $\begin{array}{l}\text { Urine neopterin per creatinine } \\
(\mu \mathrm{mol} / \mathrm{mol})\end{array}$ & 10 & 225 & $188-241$ & 18 & 204 & $157-301$ \\
\hline
\end{tabular}




\section{References}

1. Valdes-Dapena, M. A. (1980) Pediatrics 66, 597-614.

2. Kelly, D. H. \& Shannon, D. C. (1982) Pediatr. Clin. North Am. 29, $1241-1261$.

3. Scott, D. J., Gardner, P. S., McQuillan, J., Stanton, A. N. \& Downham, M. A. P. S. (1978) Br. Med. J. ii, 12-13.
4. Takashima, S., Mito, T. \& Becher, L. E. (1985) Neuropediatrics $16,76-79$.

5. Wachter, H., Fuchs, D., Hausen, A., Reibnegger, G. \& Werner, E. R. (1989) Adv. Clin. Chem. 27, 81-141.

6. Fuchs, D., Hausen. A.. Reibnegger, G., Werner, E. R., Dierich, M. P. \& Wachter. H. (1988) Immunol. Today 9, 150155. 